\title{
Preliminary results from sculpture analysis of the apiculate miospores from the Upper Visean of Kaluga region, Russia
}

\author{
Dmitriy A. Mamontov, Olga A. Orlova \\ Lomonosov Moscow State University, Faculty of Geology, Department of Paleontology; \\ Vorobievy Gory, 119899 Moscow, Russia; e-mail: palynologist.dm@mail.ru
}

(C) 2016 Authors. This is an open access publication, which can be used, distributed and reproduced in any medium according to the Creative Commons CC-BY 4.0 License requiring that the original work has been properly cited.

Palynological materials for the present study are well preserved apiculate miospores collected from palynoassemblage MS-6 of Mstikhino quarry, Kaluga Region. The unique palynoassemblage MS-6 has been extensively studied by the authors in recent years (Mamontov 2012, Mamontov \& Orlova 2014). The unusual attribute of the assemblage is a great variety of the miospores with transition apiculate sculpture (grain-coni-papillae). However, it remained unclear whether the different ornamentation types had similar ranges of variation within both the sculptural elements and arrangement of the ornaments. The general purpose of the research is comparison of similar sculptural patterns from triangular apiculate miospores based on the range of morphological variation. Preliminary results of sculpture analysis of some apiculate miospores from the locality have been obtained.

For the present study thirty specimens of each species Granulatisporites granulatus Ibrahim, Iugisporis subintortus (Kedo) Mamontov comb. nov., Lophotriletes parviverrucosus (Waltz) Kedo were accidentally sampled from the assemblage MS-6. All specimens were examined by the methods of transmitted light and scanning electron microscopy. Additionally we applied the model of sculptural analysis introduced and modified by Vezey et al. (1992). Measurements of sculptural features were carried out by the image-analyzing software ImageJ. Statistical data were summarized in the MS Excel.
Thus several sculpture variables have been measured:

- average Wadell's diameter (it is diameter of circle having a same area as a base of the sculpture elements (grain, coni or papillae));

- average height of the elements;

- average distance between the edges of adjacent elements;

- average polar diameter of spore;

- average length of the trilete rays;

- spore outline;

- quantity of elements on the visible spore hemisphere;

- quantity of elements are located along the spore equator.

Fifty measurements of the each variable were produced. Range of variation for the features was evaluated by coefficient of variation (CV).

As a result of the analysis the three species are defined by continuous variation of the polar outline between triangular concave to triangular with slightly convex sides. Similarities within shape and size of the elements were indicated. Grains, coni and papillae are characterized by similar continuous variation of apices with blunt, pointed and rounded shape. Some of the elements are supplied by bifurcating tops while the other ones are fused by the bases. Amount of the elements is differed within each species. Ornamentation of the Granulatisporites granulatus is restricted by about 290 elements of the proximal hemisphere. The same feature of the Ingisporis subintortus is defined by 
about 212 coni-like elements. In contrast the Lophotriletes parviverrucosus are attributed by about 170 sculptural unites. All specimens of Iugisporis are characterized by medium coefficient of variation $26 \%$ for diameter of the base of the coni (Wadell's diameter), but the CV of height of the elements is about 35\%. Variation of the distance between the coni is extremely high $60 \%$. For the Lophotriletes specimens CV of the Wadell's diameter is increased up to $30 \%$ and variation of the height of papillae became more stronger - $44 \%$. However, there are no differences in CV of the distance between the papillae in comparison to the Ingisporis. Coefficient of variation of Wadell's diameter for specimens of Granulatisporites is indicated by level $25 \%$. Variability of grain height is about to $30 \%$. However, variance of distance between the adjacent grains is decreased up to $40 \%$ in contrast to other species. Variation of the polar diameter and length of rays from the all specimens are inconspicuous changed up to $12 \%$. Additionally specimens of the all species are marked by correlation between amount of elements along the spore equator and concavity of the interradial sides of spore outline. Quantity of the equatorial elements was salutatory increased while the interradial sides became more concave. However it would generally depend on the average polar diameter of the spores. Significantly, size of the sculptural elements unevenly increased ongoing from polar area to equatorial margin of the spores. In additional, continuous variation between granulate, coni and papillae ornamentations have been observed within the studied specimens. Accordingly, all morphological features of the genera Granulatisporites, Iugisporis, Lophotriletes were subdivided into three categories:

1) common characteristics which are more stable: polar diameter, length of rays, spore outline;

2) variable characteristics which are defined by high coefficient of variation: quantity of elements, height of the elements, distance between the edges of adjacent elements, Wadell's diameter;
3) variable qualitative characteristics: shape, type and distribution of sculptural unites.

The results lead us to believe that such qualitative characters as type, shape and arrangement of sculpture elements are strongly connected with measured $\mathrm{CV}$ of characteristics from b) category. In accordance to morphon concept introduced by van der Zwan (1979) the group of miospore species is united in morphon by similar continuous variation of morphological features. Therefore, such morphologically similar species have the same range of $\mathrm{CV}$ of the coincident sculpture features. However it should be noted that this conclusion are restricted by common occurrence of transitional sculpture variations of the apiculate spores. Also it is possible that different value CV from different variables were caused by the different role of the sculptural feature in natural selection.

The research was supported by Russian Foundation for Basic Researches, project No 15-04-09067.

\section{REFERENCES}

Mamontov D.A., 2012. Pervyye Rezul'taty Palinologicheskogo Izucheniya Verkhnevizeyskikh Otlozheniy Mstikhinskogo Kar'yera (Kaluzhskaya Oblast'). [in:] Sovremennaya paleontologiya: klassicheskiye $i$ noveyshiye metody. Devyatayaaya Vserossiyskaya Nauchnaya Shkola Molodykh Uchenykh-Paleontologov. 1-3 oktyabrya 2012 g. Tezisy Dokladov, Paleontologicheskiy institut im. A.A. Borisyaka, Rossiyskaya akademiya nauk, Moskva, $32-33$.

Mamontov D.A. \& Orlova O.A., 2014. Palynological characteristics of the Upper Visean deposits from the Mstikhino quarry, Kaluga Region. Moscow University Geology Bulletin, 69, 1, 28-35.

Vezey L.E., Shah V.P. \& Skvarla J.J., 1992. A numerical approach to pollen sculpture terminology. Plant Systematics and Evolution, 181, 245-254.

Zwan C.J. van der, 1979. Aspects of Late Devonian and Early Carboniferous palynology of southern Ireland. I. The Cyrtospora cristifer morphon. Review of Palaeobotany and Palynology, 30, 133-155. 